Assessing the impacts of integrating snowpack error distribution in the management of a hydropower reservoir using Bayesian Stochastic Dynamic Programming (BSDP)

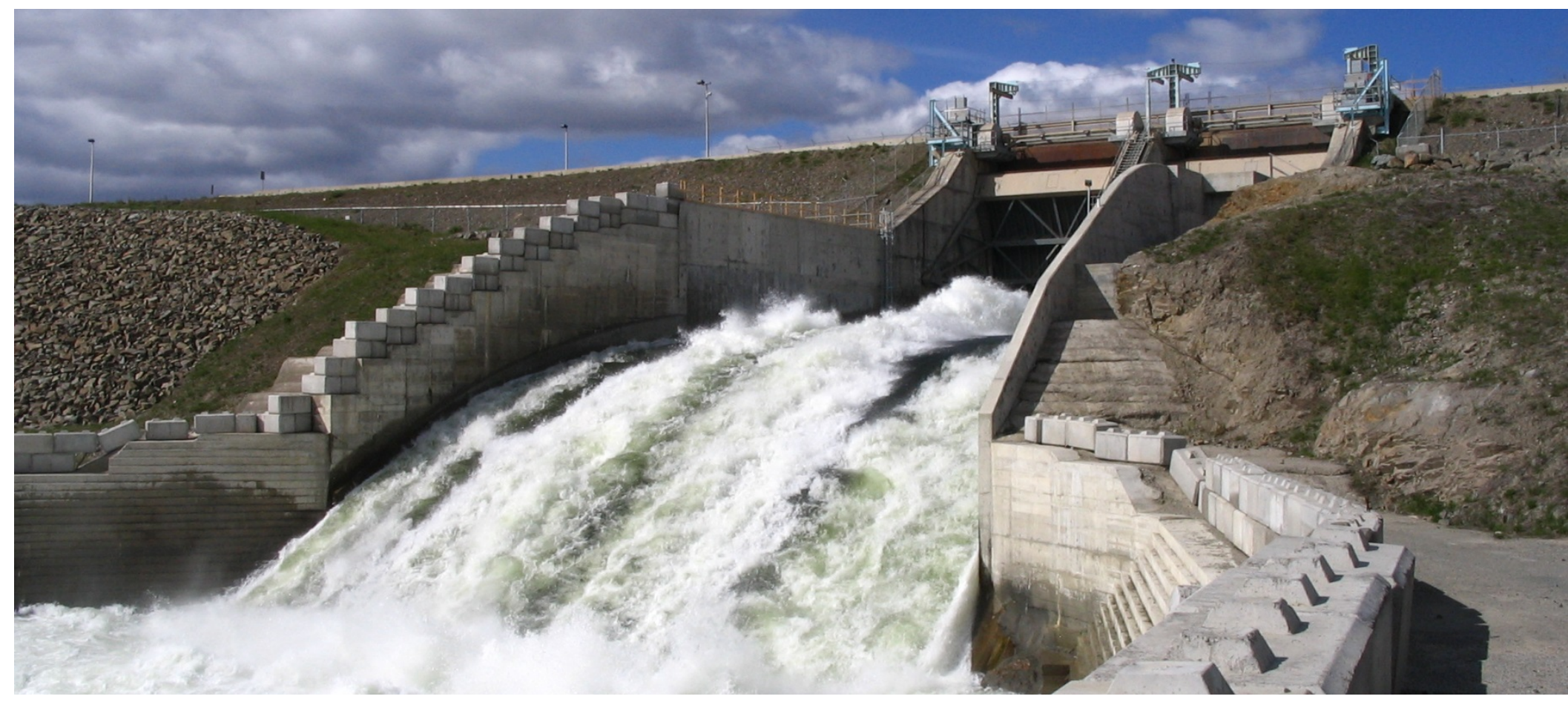

Richard Arsenault*, Pascal Côté and Marco Latraverse

École de technologie supérieure

Department of construction engineering

Montréal (QC), Canada, H3C1K3

+1-514-396-8743

Richard.arsenault@etsmtl.ca 
ÉTS Hydropower System

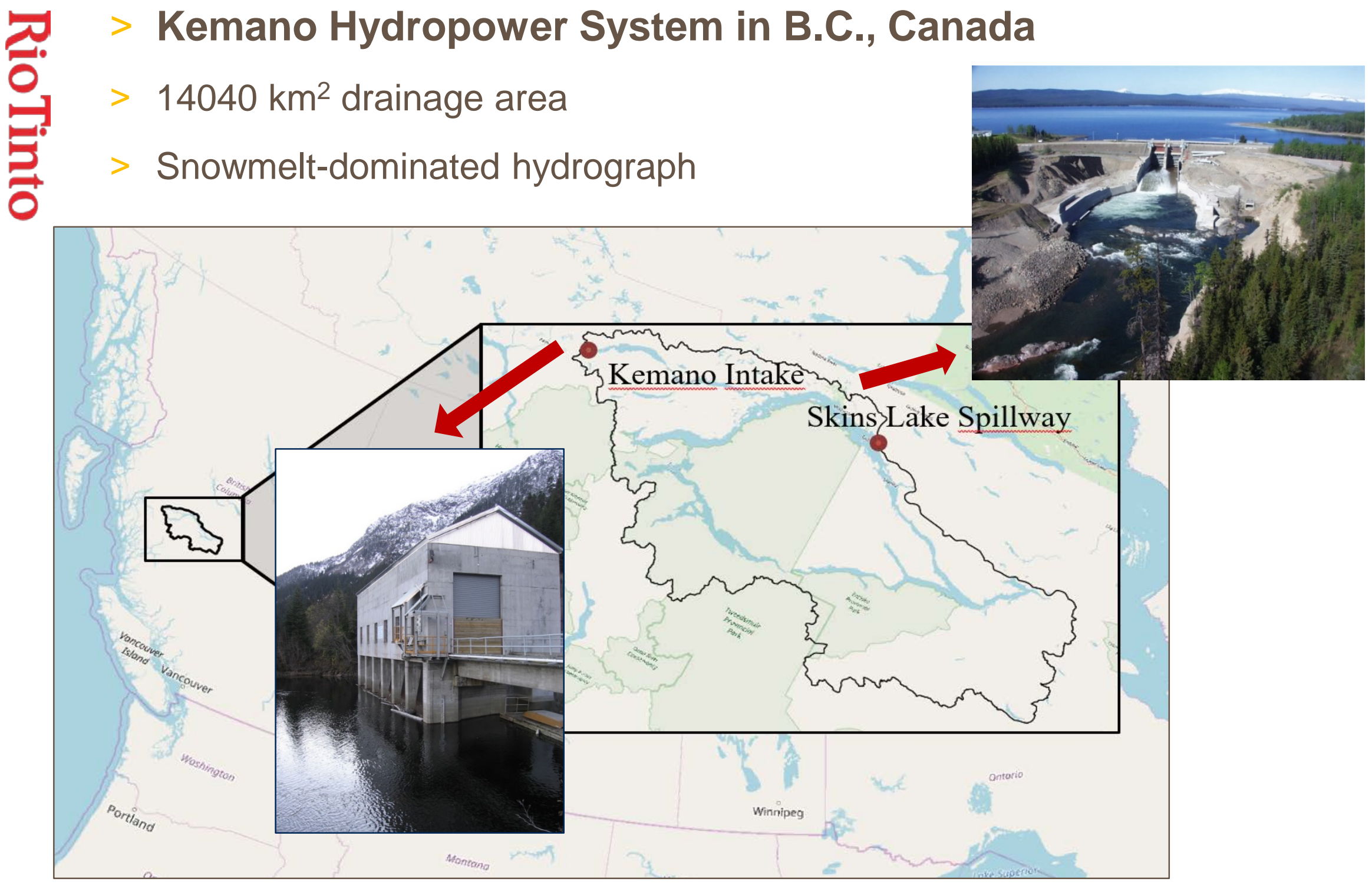




\section{Hydropower System}

$>$ Rio Tinto Kemano System in B.C. Canada

$>$ Water release decisions aided by an SDP implementation

$>$ A hydrological variable representing the water content of the catchment, including Snow-Water Equivalent (SWE), is used as a predictive variable of future inflows in SDP

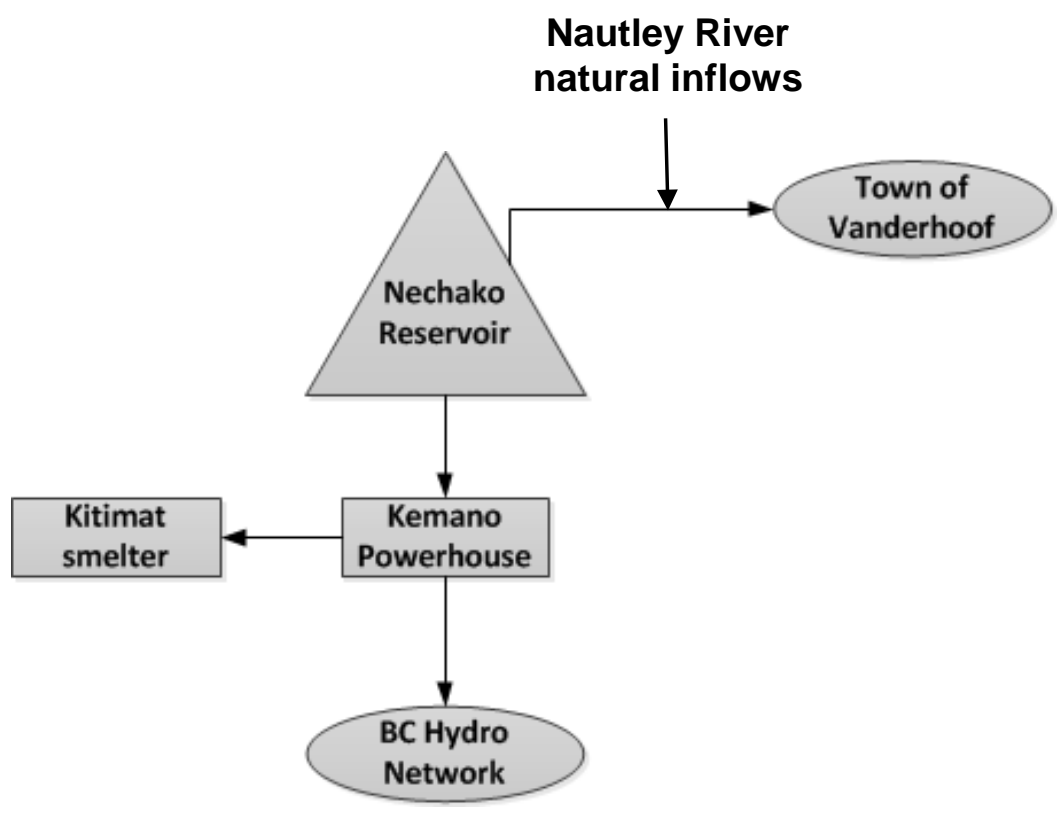




\section{Challenges}

$>$ Impact of snowmelt is paramount in the management of the hydropower system.

$>$ High uncertainty around SWE measurements (4 snow pillows, 7 core-sampling sites)

$>$ Spatial variability of SWE is very high $(2000 \mathrm{~mm}$ precip. in the mountains, $400 \mathrm{~mm}$ in the plains)

\section{Objective:}

$>$ Evaluate uncertainty around hydrologic variables (including SWE) and use this information to improve the water release policy in a Stochastic Dynamic Programming Framework 


\section{Methods}

\section{> Distributed hydrological model (CEQUEAU) - 2 simulations}

(1) Ordinary simulation, using actual measured Precip. and Temp.

(2) «Pseudo-Perfect » simulation, using fitted Precip. and Temp. timeseries to perfectly reproduce inflows;

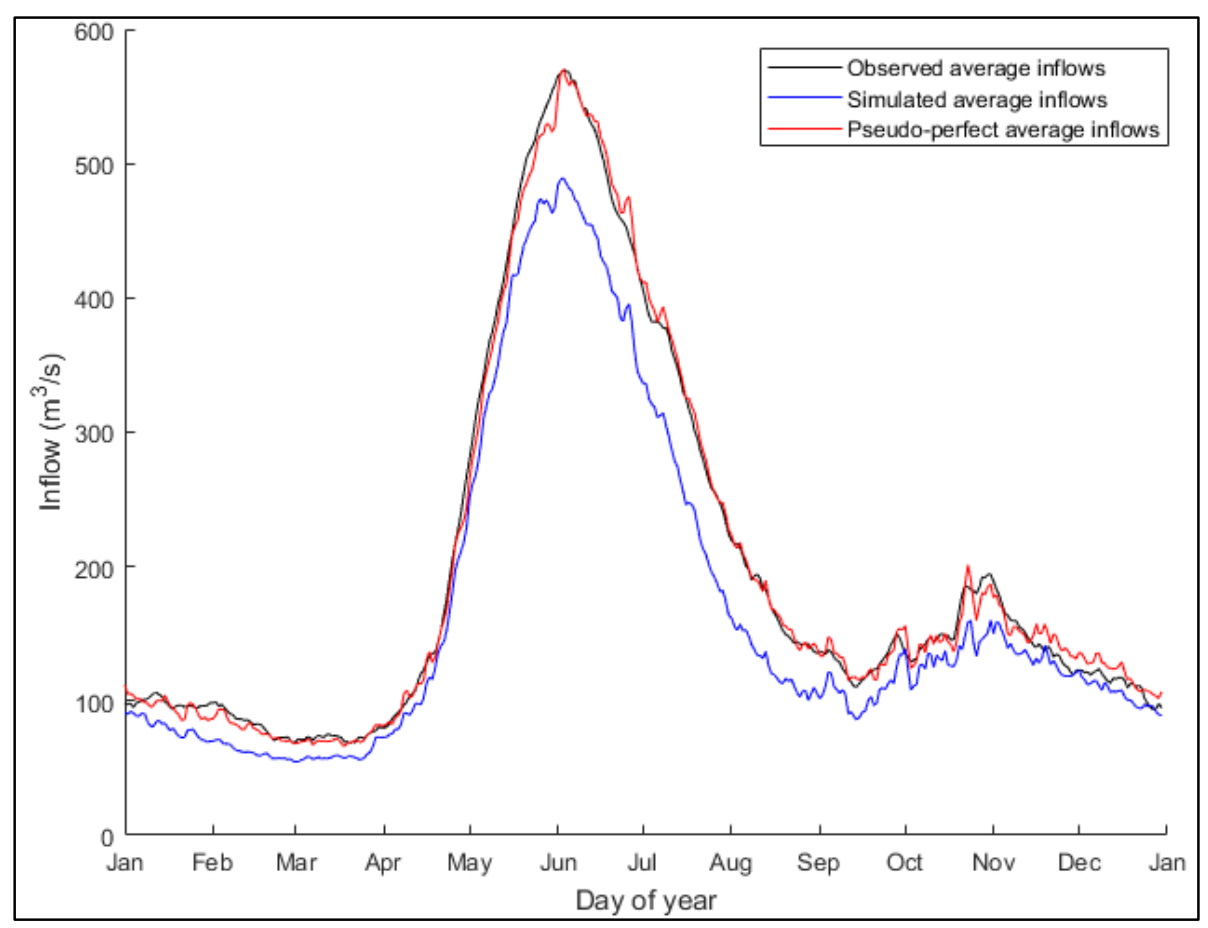

$>$ Each simulation also returns state variables, such as SWE

$>$ We can estimate the bias and uncertainty in the hydrologic variable by comparing both simulations 


\section{Methods}

$>$ Current Policy given by SDP:

$$
\pi_{t}\left(s_{t}, h_{t}\right)=\underset{u_{t}}{\operatorname{argmax}}\left\{\underset{q_{t} \mid h_{t}}{\mathrm{E}}\left[B_{t}\left(s_{t}, u_{t}, q_{t}\right)+\underset{h_{t+1} \mid h_{t}}{\mathrm{E}}\left[F_{t+1}\left(s_{t+1}, h_{t+1}\right)\right]\right]\right\}
$$

$>$ With the water value function computed as:

$$
F_{t}\left(s_{t}, h_{t}\right)=\max _{u_{t}}\left\{\underset{q_{t} \mid h_{t}}{\mathrm{E}}\left[B_{t}\left(s_{t}, u_{t}, q_{t}\right)+\underset{h_{t+1} \mid h_{t}}{\mathrm{E}}\left[F_{t+1}\left(s_{t+1}, h_{t+1}\right)\right]\right]\right\}
$$

$>$ However, operationally we do not have perfect values.

$>$ In operations, we add the error distribution of $h_{t}$ in the SDP policy:

$$
\pi_{t}\left(s_{t}, h_{t}\right)=\underset{u_{t}}{\operatorname{argmax}}\left\{\underset{h_{t} \mid \hat{h}_{t}}{\mathrm{E}}\left[\underset{q_{t} \mid h_{t}}{\mathrm{E}}\left[B_{t}\left(s_{t}, u_{t}, q_{t}\right)+\underset{h_{t+1} \mid h_{t}}{\mathrm{E}_{t}}\left[F_{t+1}\left(s_{t+1}, h_{t+1}\right)\right]\right]\right]\right\}
$$

$>$ Where the error distribution of $h_{\mathrm{t}}$ is computed and updated at the end of each season when the pseudo-perfect weather timeseries can be generated. 


\section{Results}

\section{$>$ Error distribution relative to the season}

The hydrological variable also includes soil humidity, which is negligible in winter but becomes important in summer. Units in $\mathrm{mm}$ of water.
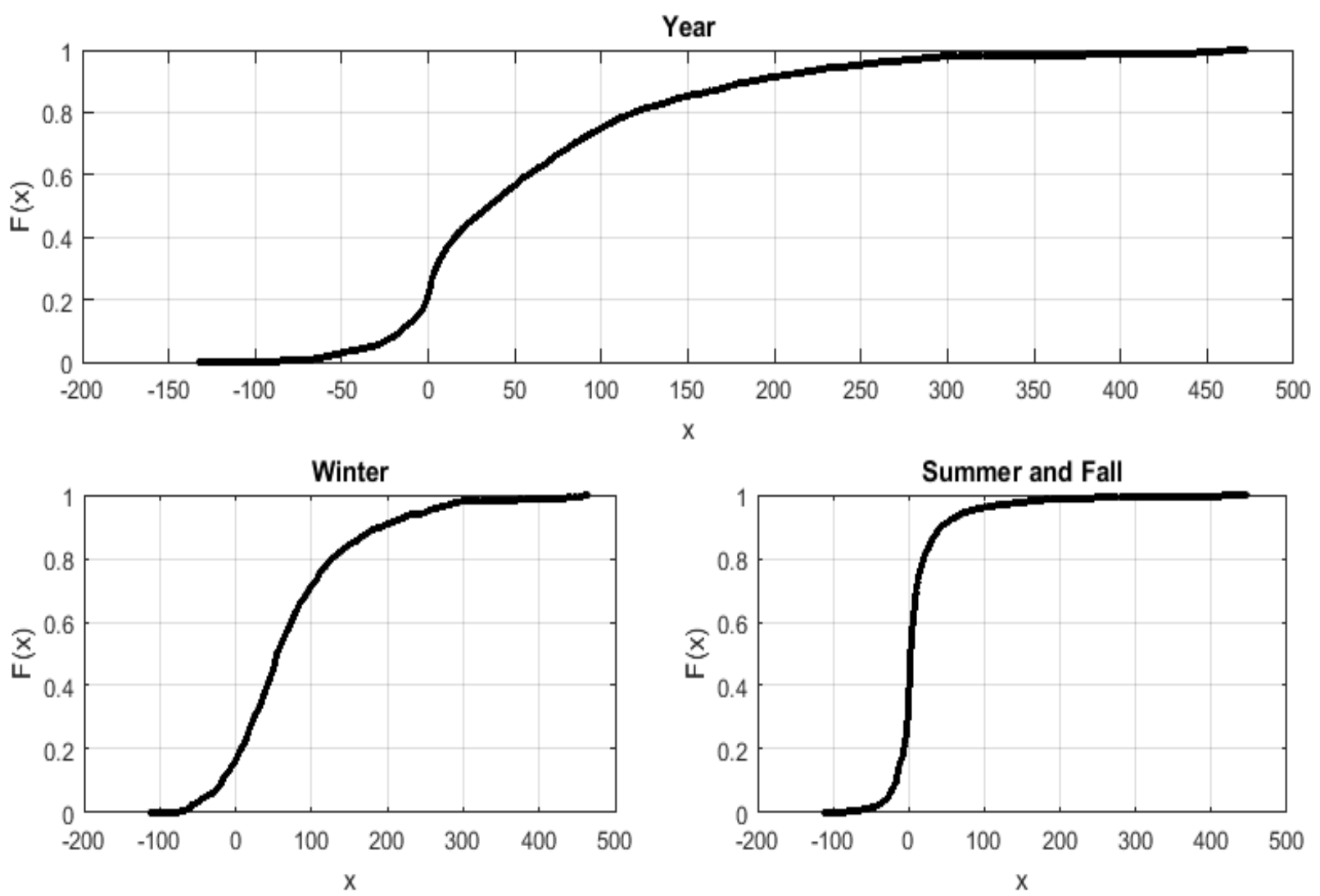


\section{Simulation Results}

\section{$>$ Impact on water management}

\begin{tabular}{lccc}
\hline Hydrological Variable & $\begin{array}{c}\text { Avg. Annual } \\
\text { Export and } \\
\text { Aluminum }\end{array}$ & $\begin{array}{c}\text { Daily } \\
\text { Probability of } \\
\text { Shortage }\end{array}$ & $\begin{array}{c}\text { Daily } \\
\text { Probability of } \\
\text { Flooding }\end{array}$ \\
\hline Pseudo-perfect Corrected & 106.1 & $6,5 \%$ & $0,1 \%$ \\
Real, No Distribution & 100.0 & $6,0 \%$ & $0,5 \%$ \\
Real, With Distribution & 103.1 & $6,0 \%$ & $0,2 \%$ \\
\hline
\end{tabular}

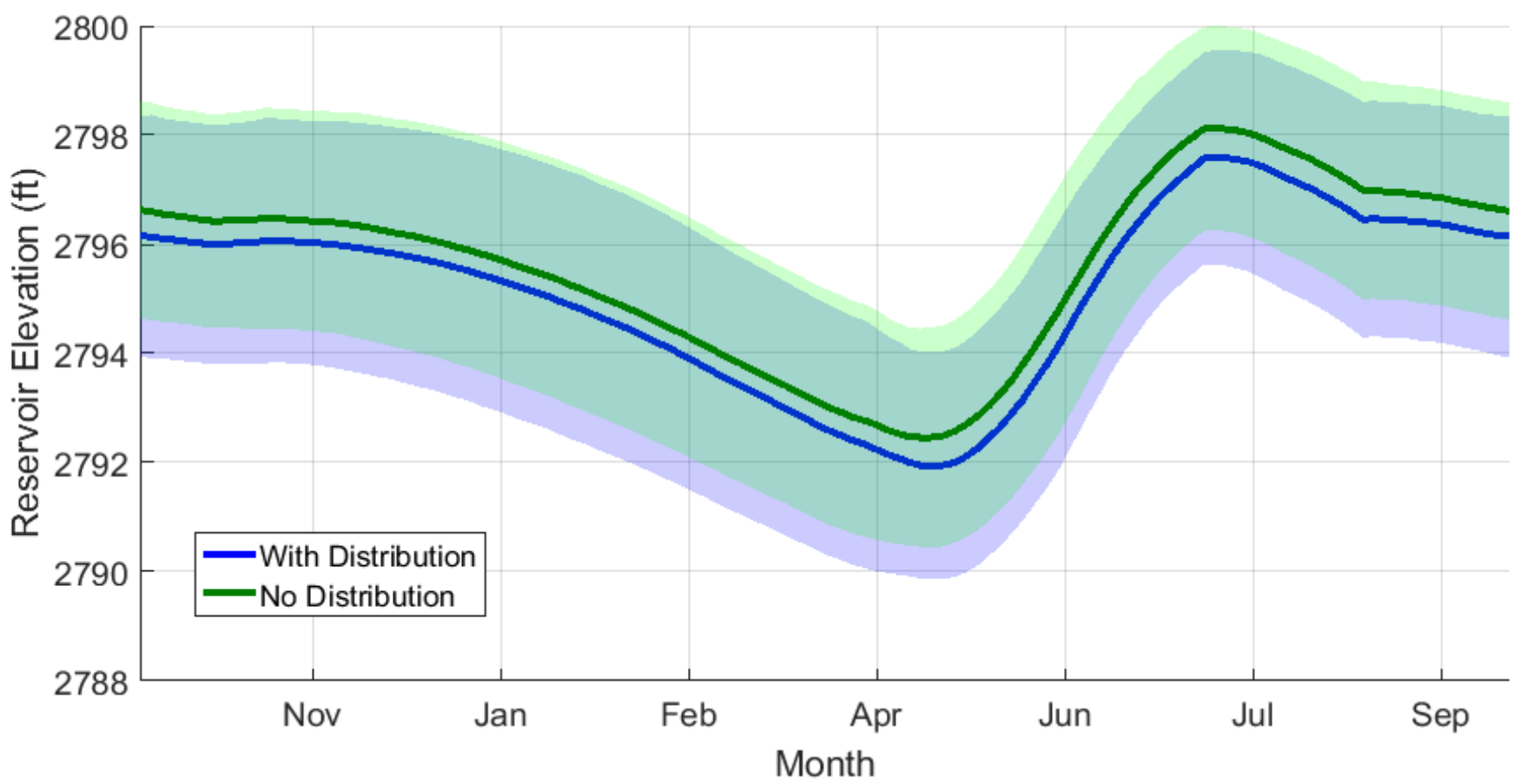




\section{Analysis and conclusions}

> BSDP naturally corrects the Hydrologic Variable bias

$>$ Lower reservoir level on average: probably due to correction of precipitation undercatch

$>$ More efficient generation due to better uncertainty representation

$>$ Less flooding, more energy for same shortage risk.

> Bayesian SDP has shown to be a promising water resources management tool

> Pseudo-perfect simulations can be very valuable to estimate the error distributions (rather than embarking on measurement field trips) 
Assessing the impacts of integrating snowpack error distribution in the management of a hydropower reservoir using Bayesian Stochastic Dynamic Programming (BSDP)

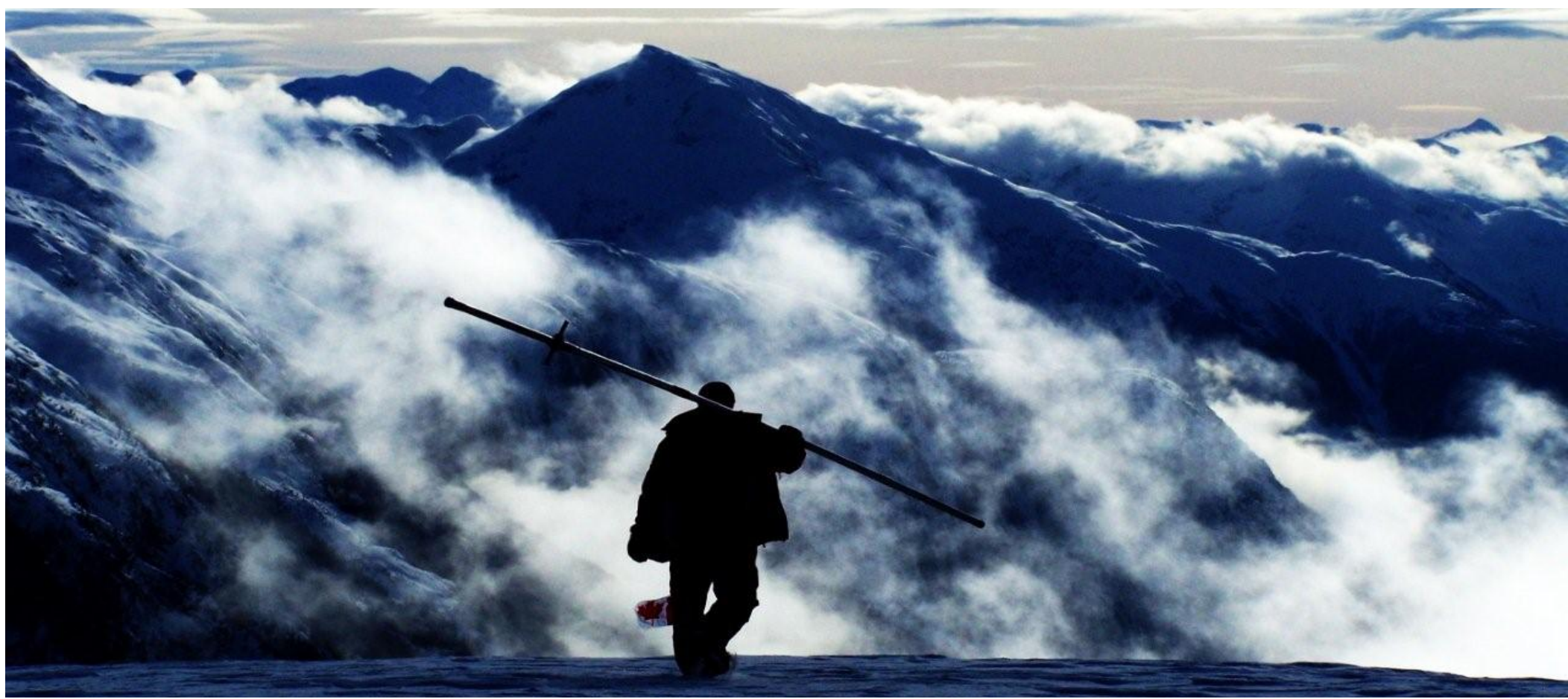

Richard Arsenault*, Pascal Côté and Marco Latraverse

École de technologie supérieure

Department of construction engineering

Montréal (QC), Canada, H3C1K3

+1-514-396-8743

Richard.arsenault@etsmtl.ca 